\title{
Photochemical Cleavage of Benzylic C-N Bond to Release Amines
}

Pengfei Wang,* Dattatray A. Devalankar, and Wenya Lu

Department of Chemistry, University of Alabama at Birmingham, Birmingham, Alabama 35294, United States

Table of Content 


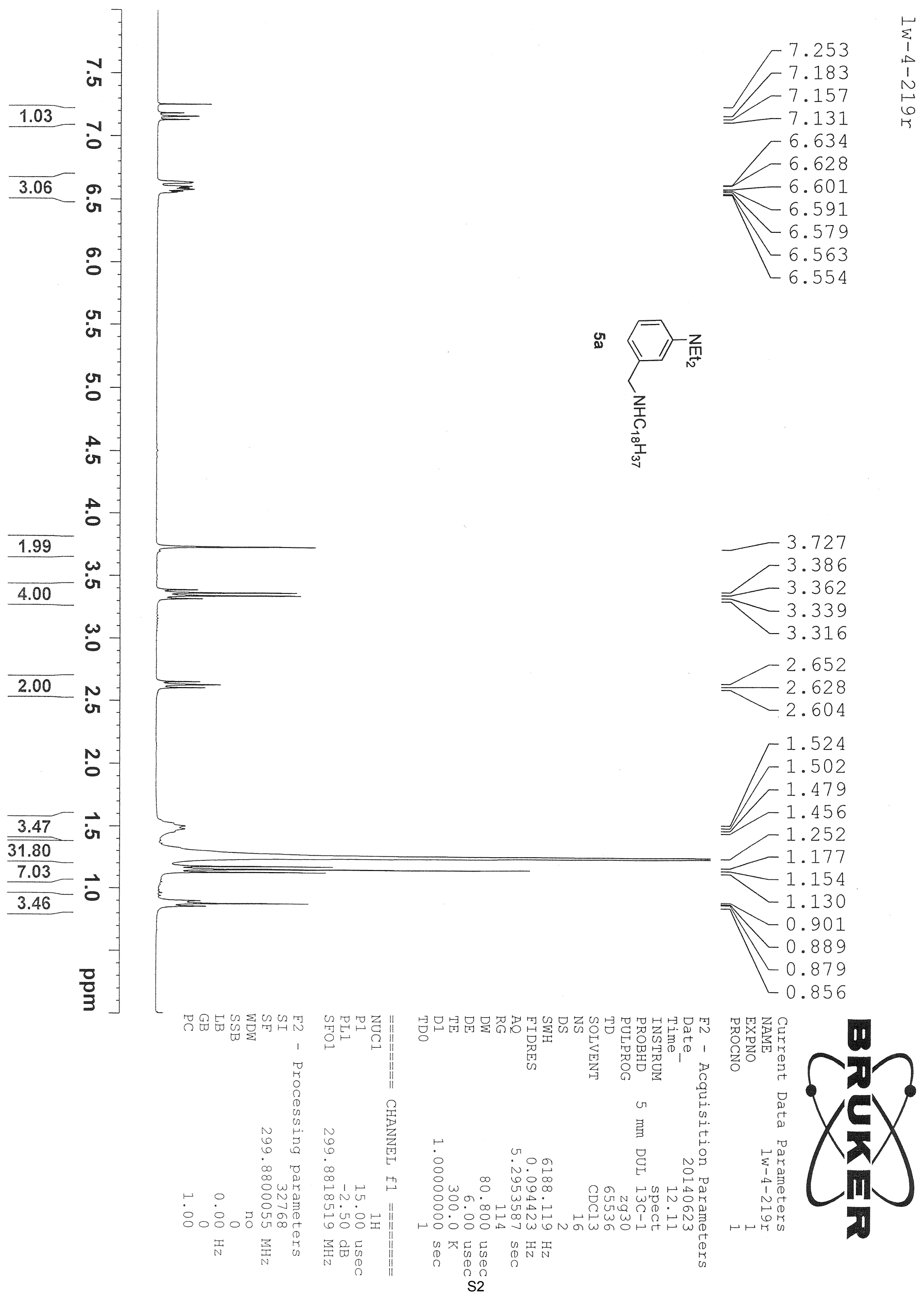




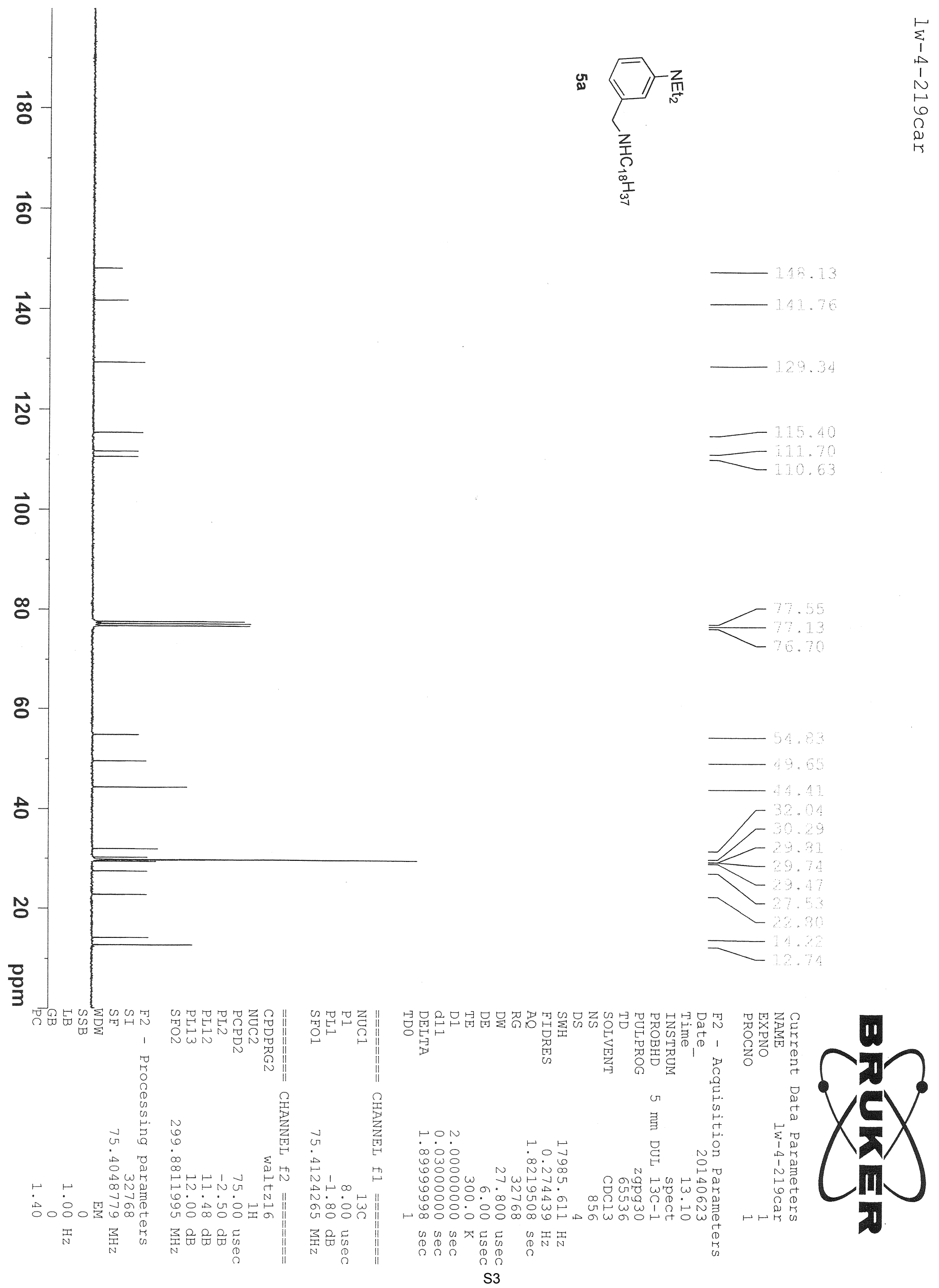




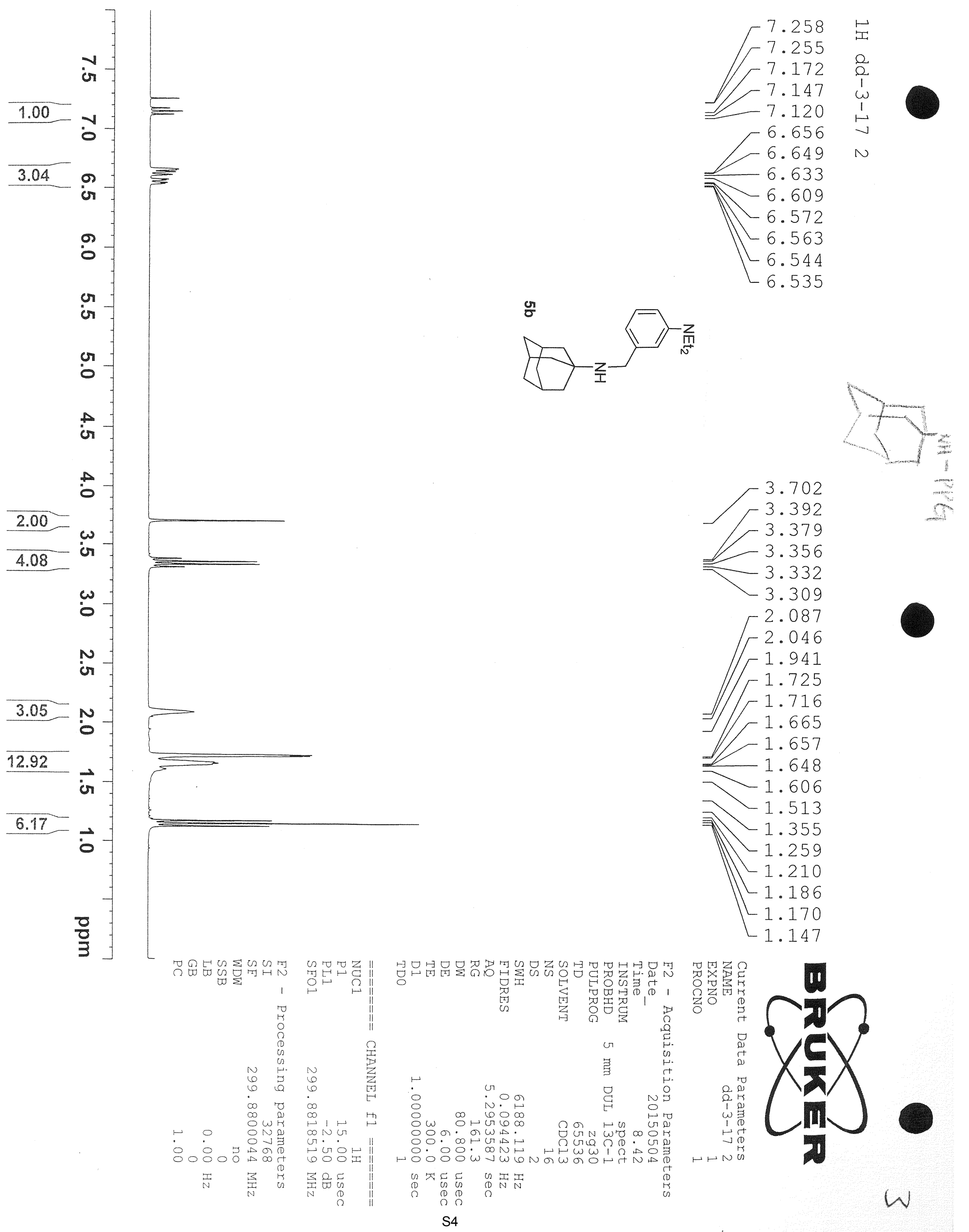



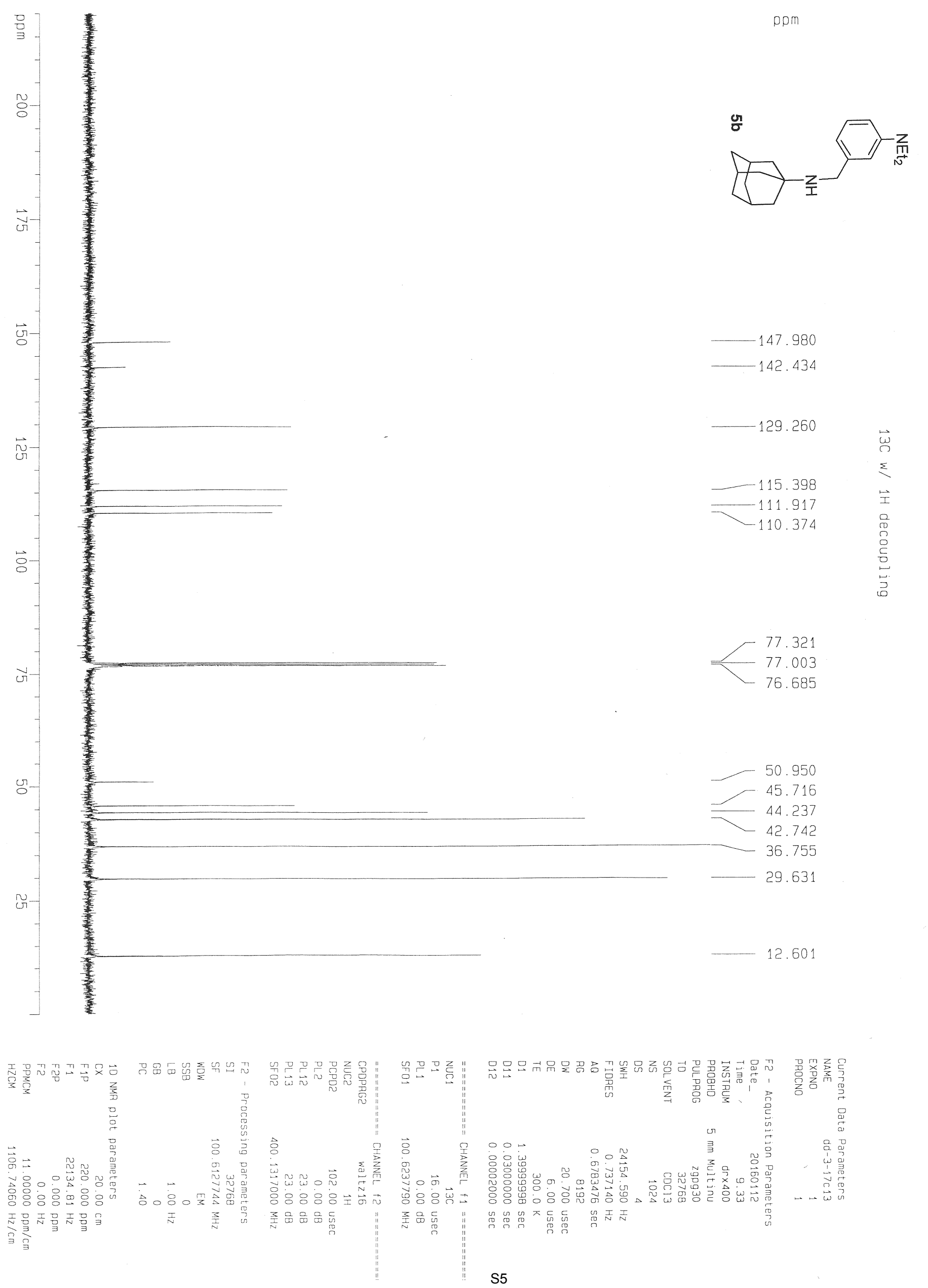


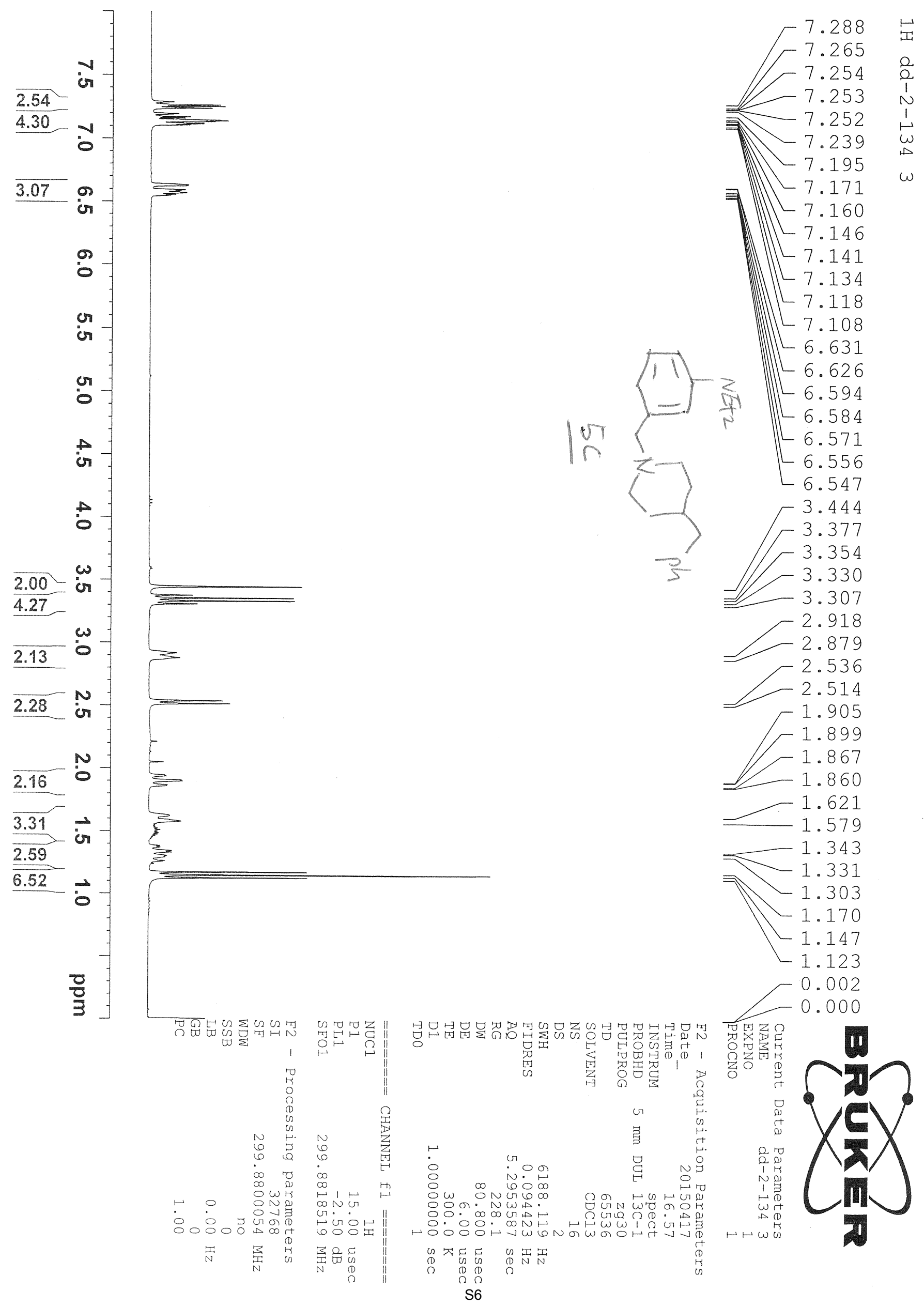



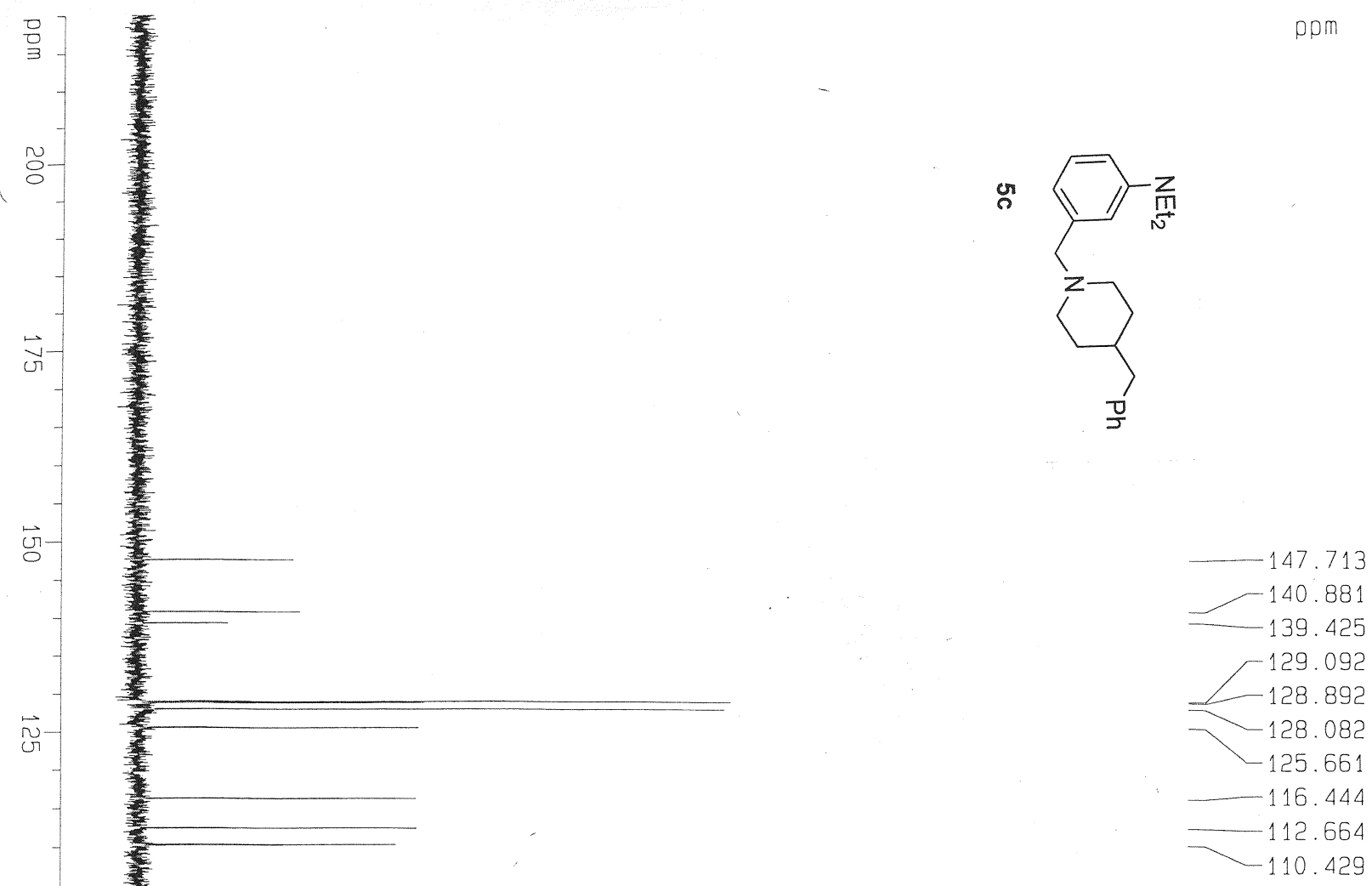

ᄋ

৫্

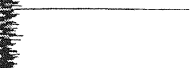

39.425

29.092

$\overleftrightarrow{\sim}$

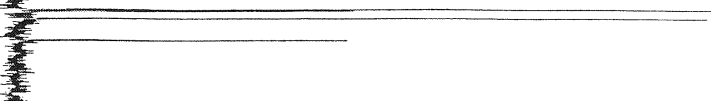

77.317

77.000

76.682

63.976

桻

$-53.783$

$-44.300$

43.276

37.963

32.278

U

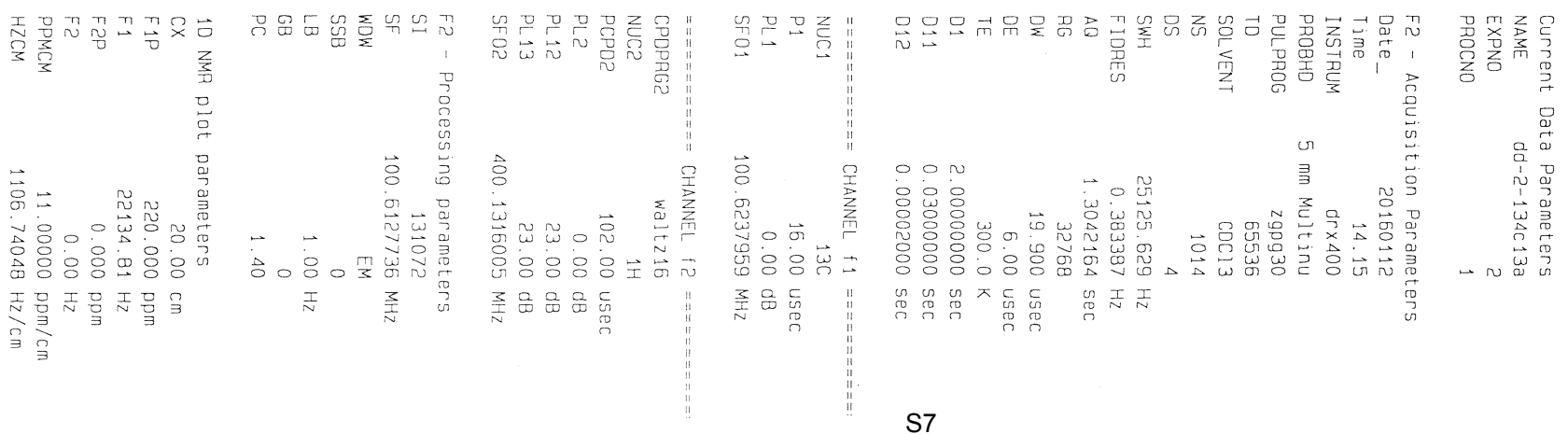




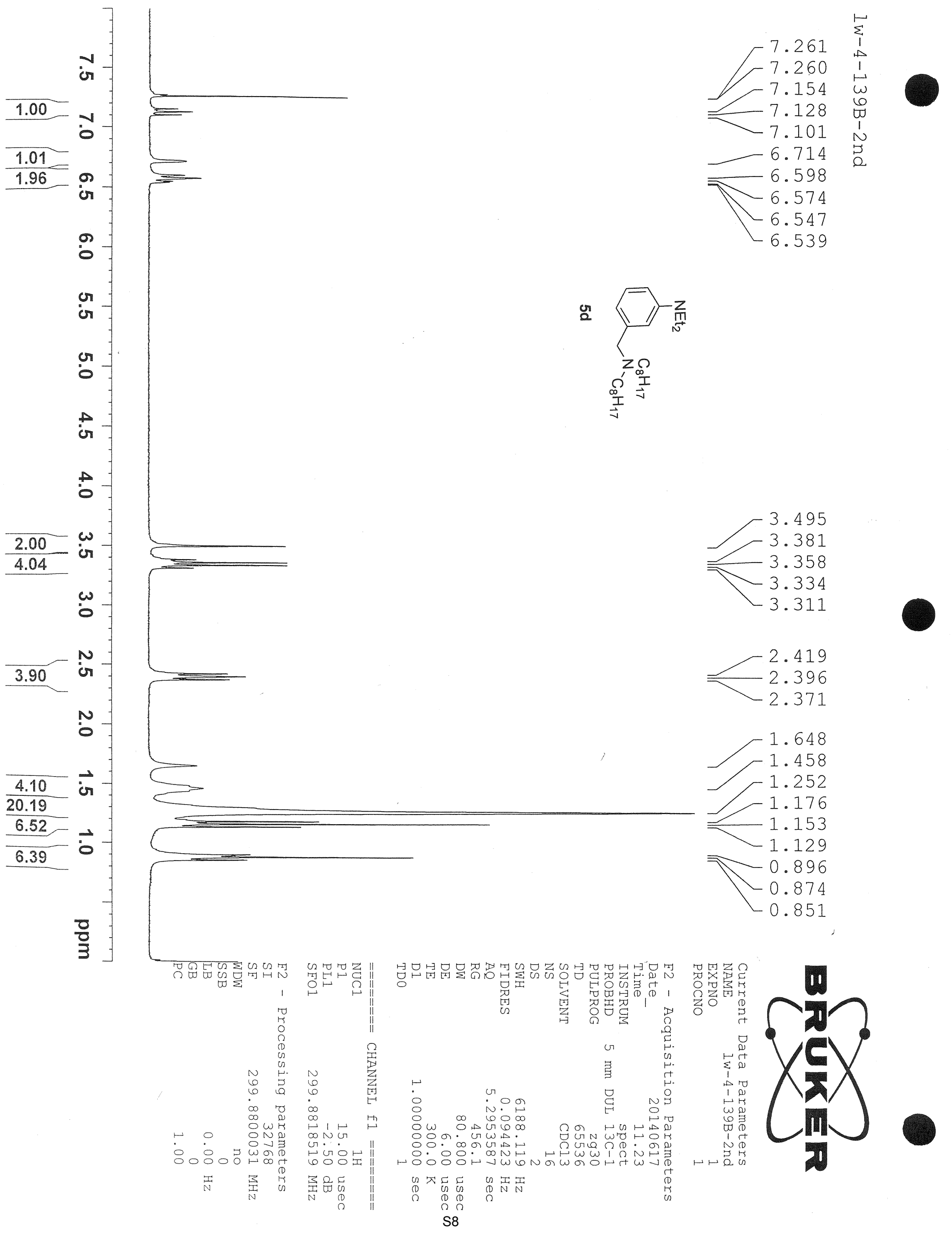




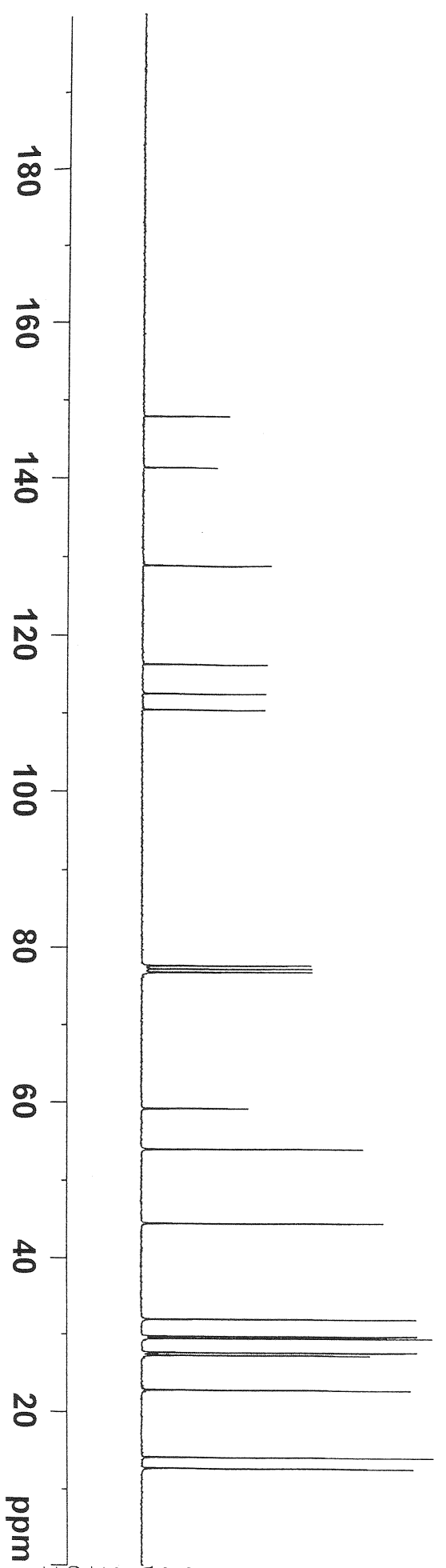

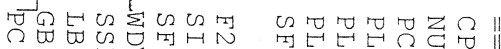

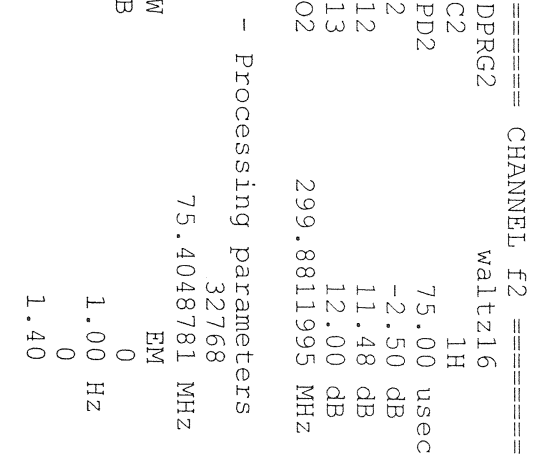

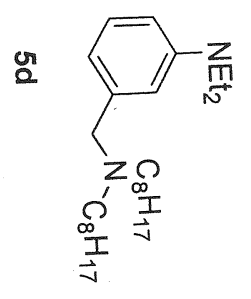

$-147.94$

$-141.39$

128.92

116.28

112.50

$-110.46$

77.57

77.15

$-76.73$

59.19

53.99

44.49

32.03

29.77

29.71

29.51
-27.68

$\checkmark 27.32$

14.23

$-12.78$

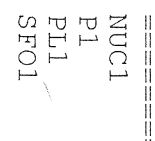

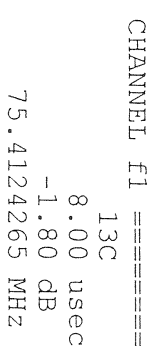

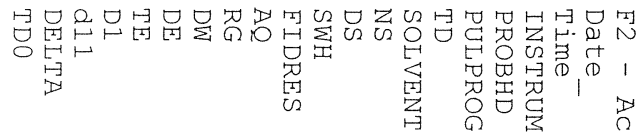

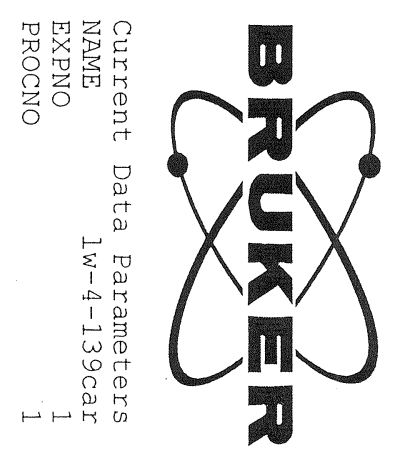

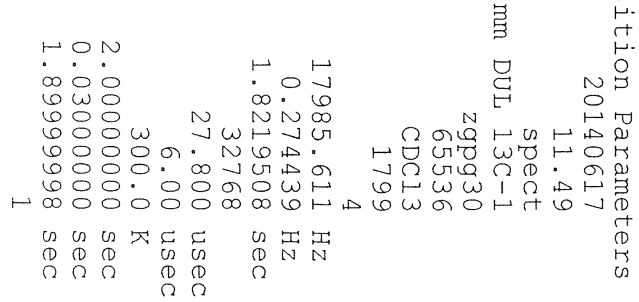




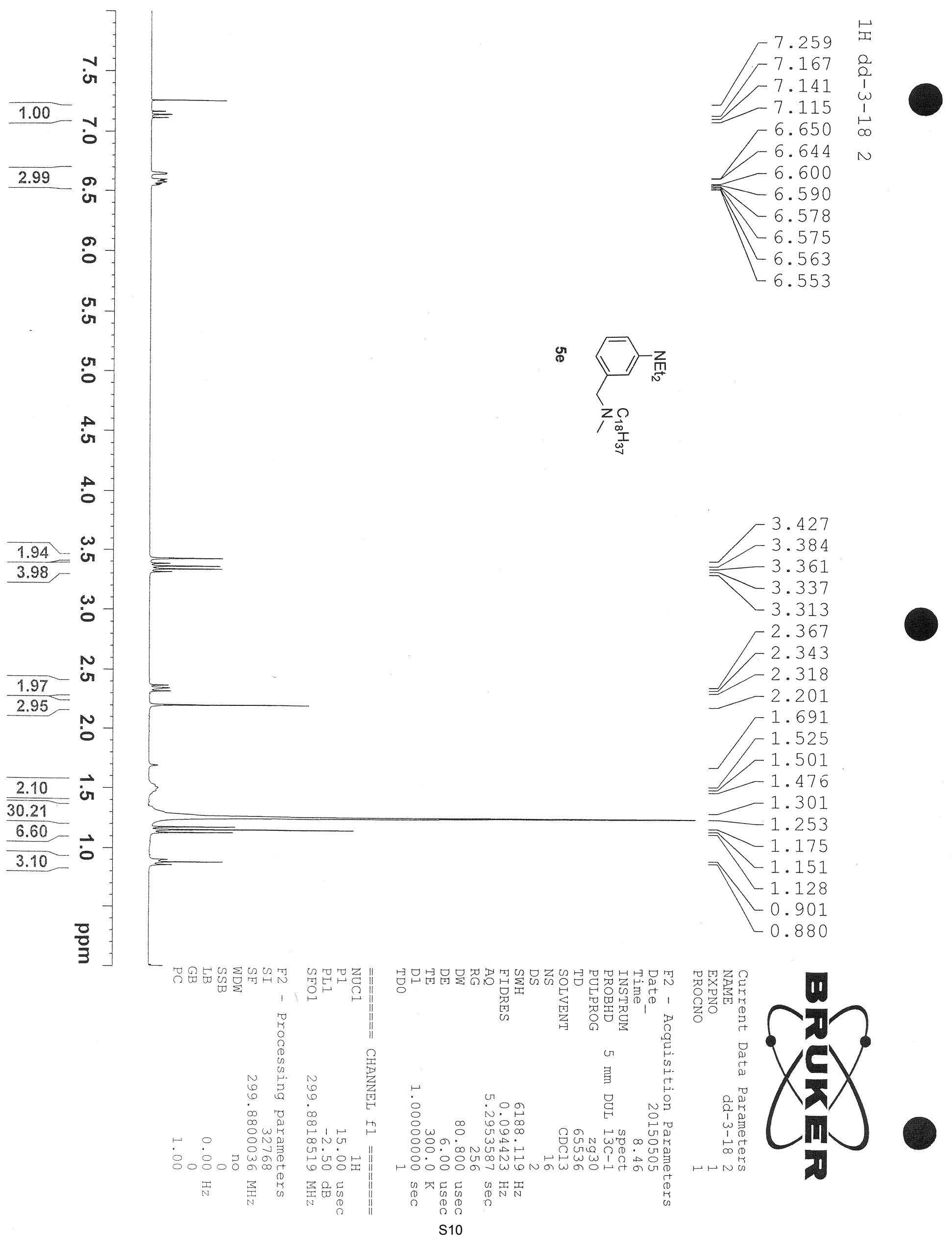




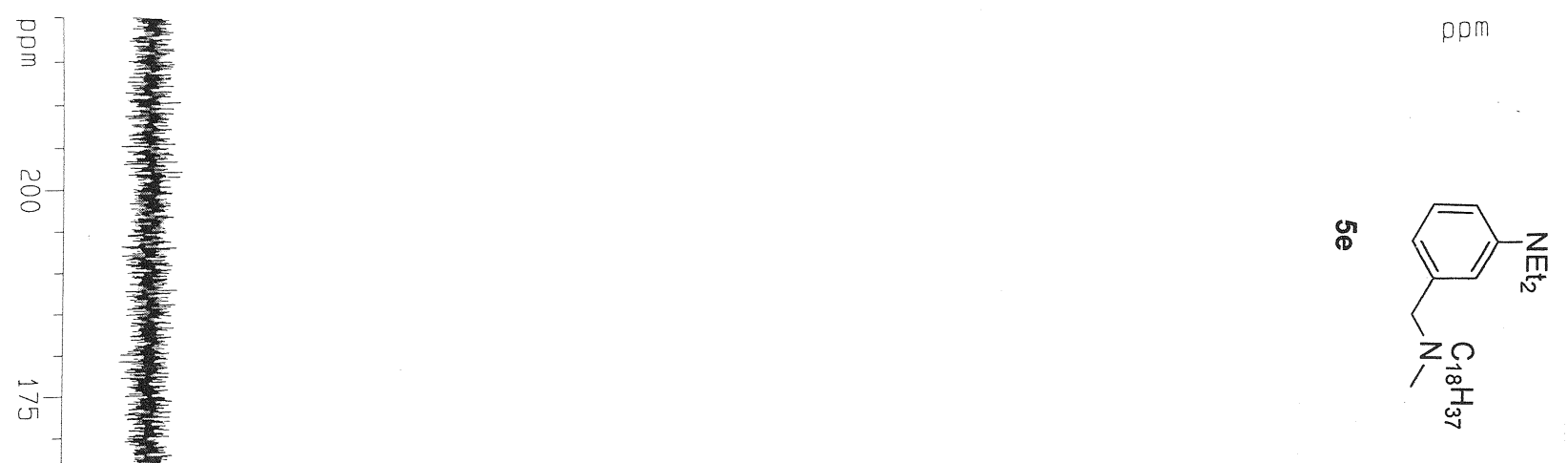

ज़

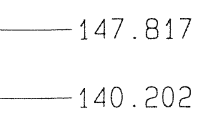

128.932

$\stackrel{\vec{\omega}}{\circ}$

㟧
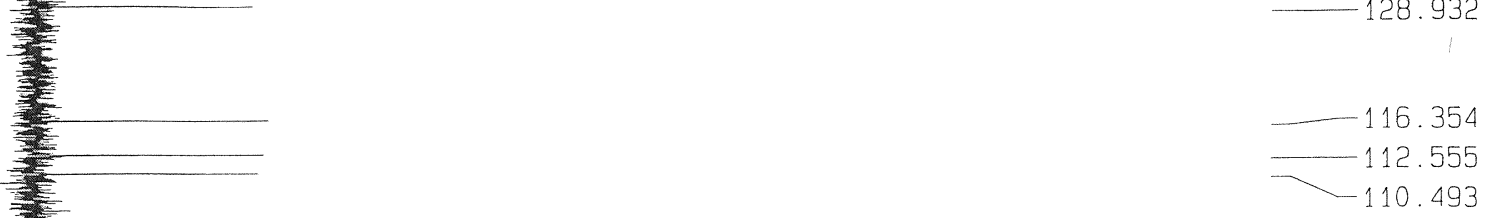

$\Sigma$

宔

몸

응-

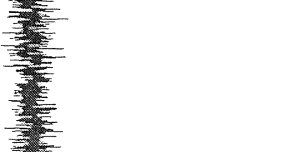

$-110.493$

77.317

77.199

$-76.999$

76.682

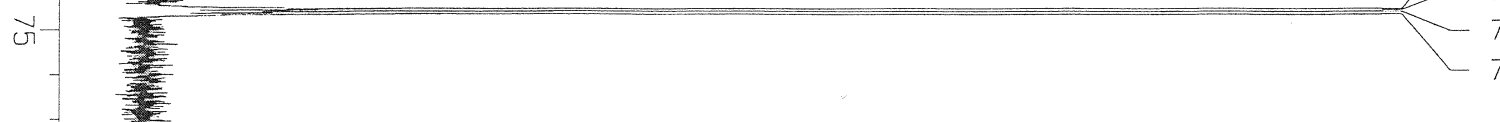

$-62.913$

57.464

g-

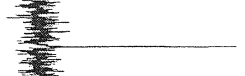

57.464

44.294
$-\begin{array}{r}42.413 \\ -31.919\end{array}$

f 29.692

$-29.652$

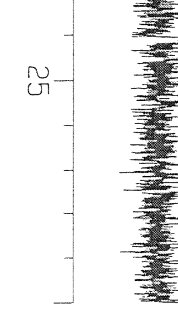

$-29.356$

27.510
-27.469

的

27.469
-22.685

$-14.115$

$-12.610$

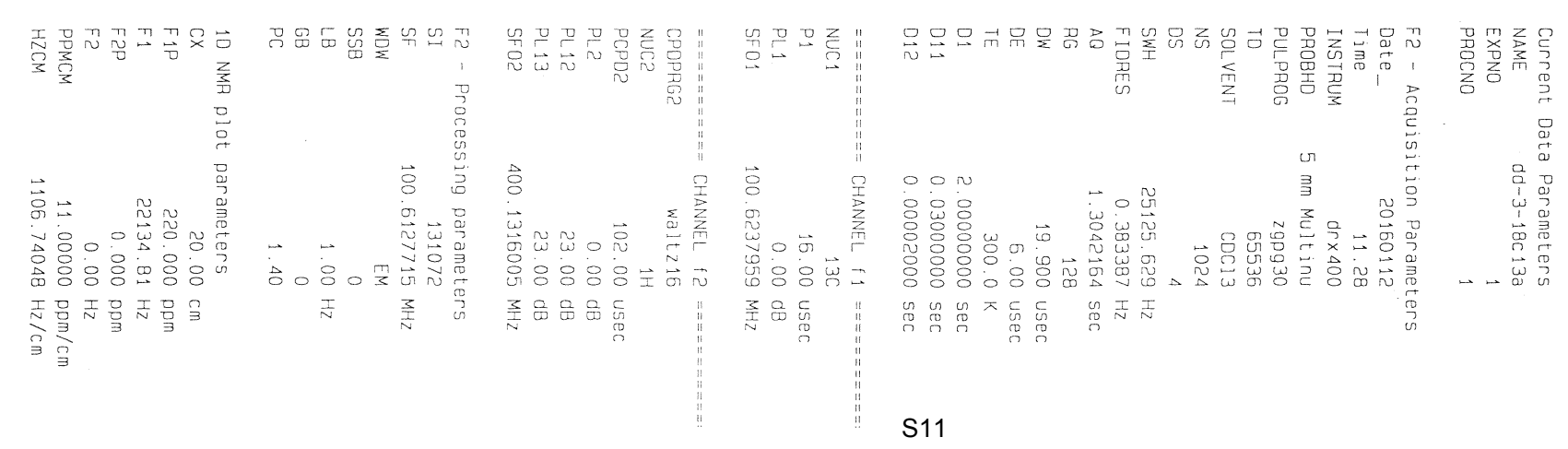




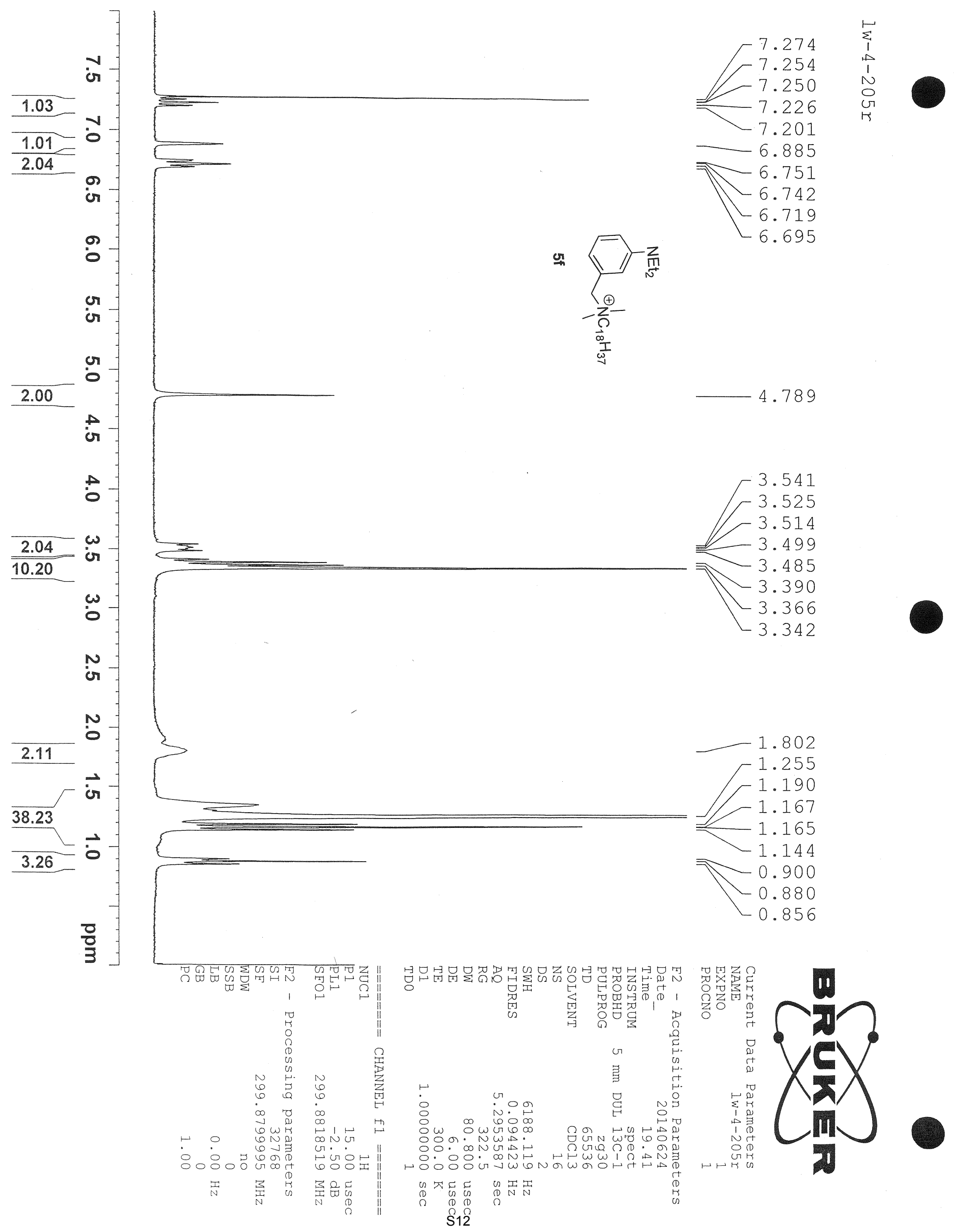




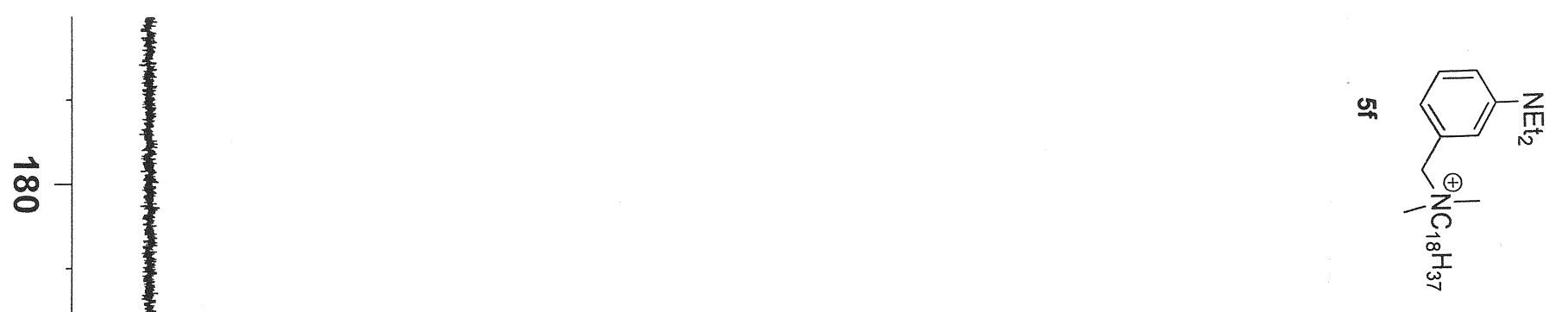

$\overrightarrow{\overrightarrow{0}}$

$$
\overrightarrow{\vec{a}}
$$

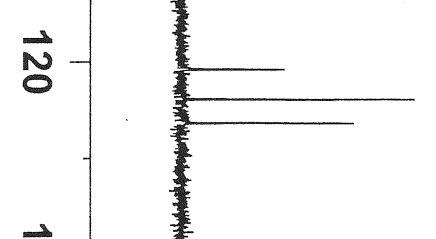

130.06

128.23

$\overrightarrow{\mathrm{a}}$

ஃ

8

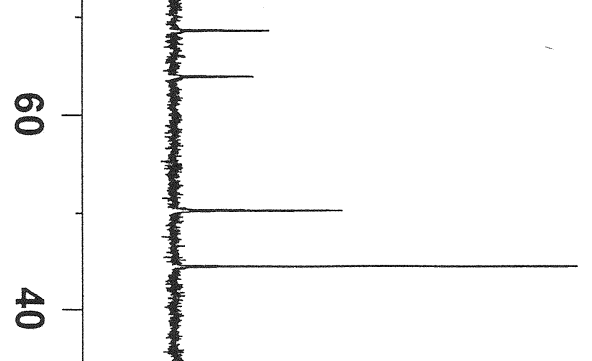

119.15

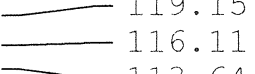

$-113.64$
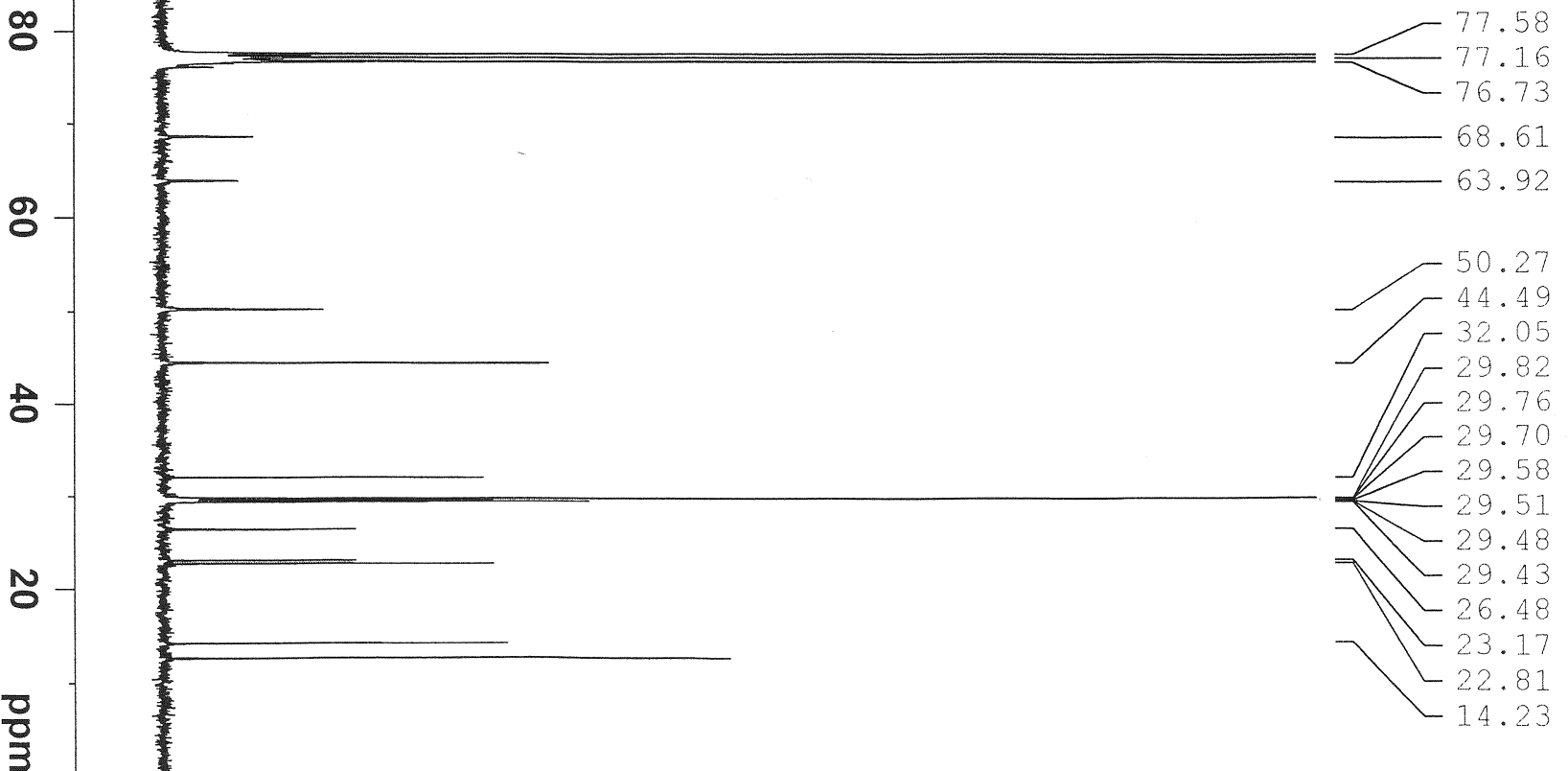

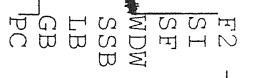

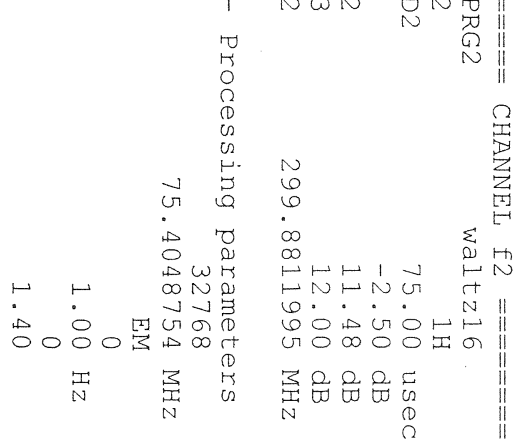

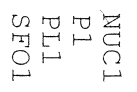

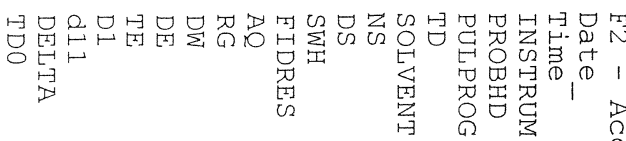

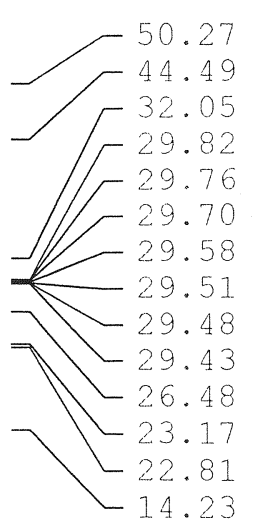

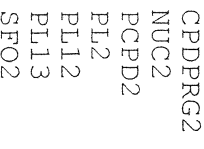

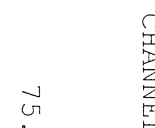

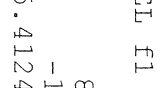

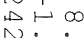

Nid

督查总

\section{.

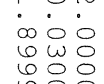

$608 \omega \sim \mathcal{N} \sim \sim N$

6080.0 N

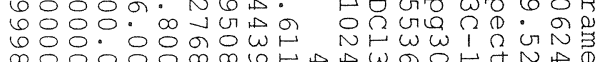

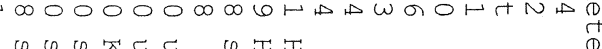

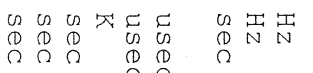

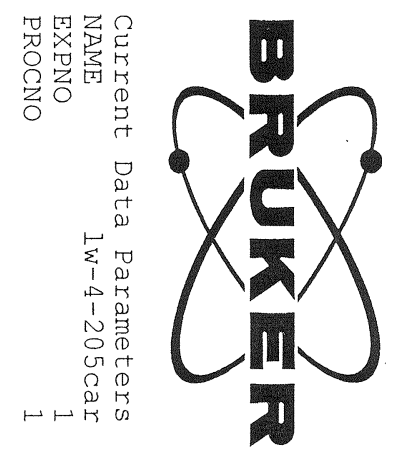



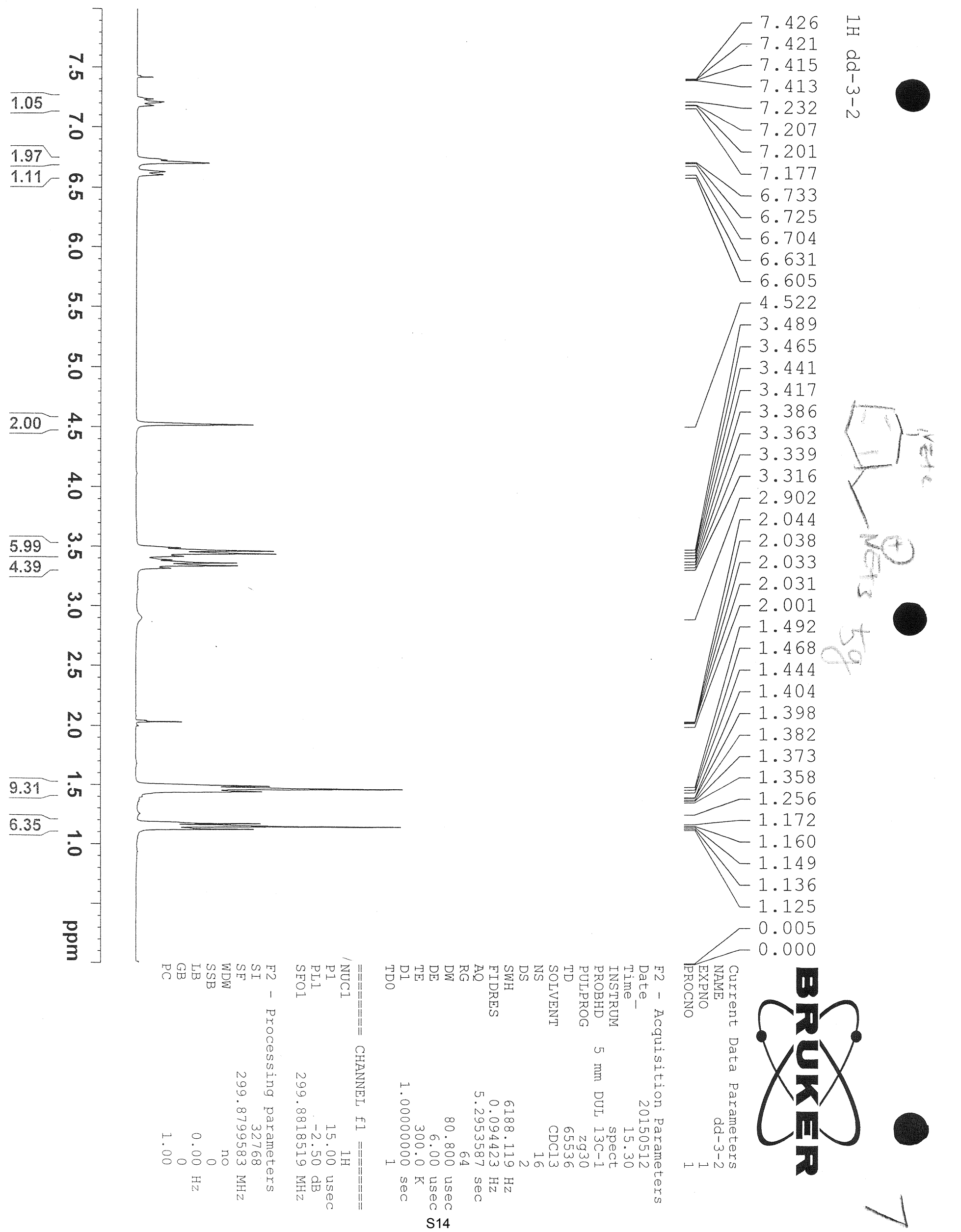

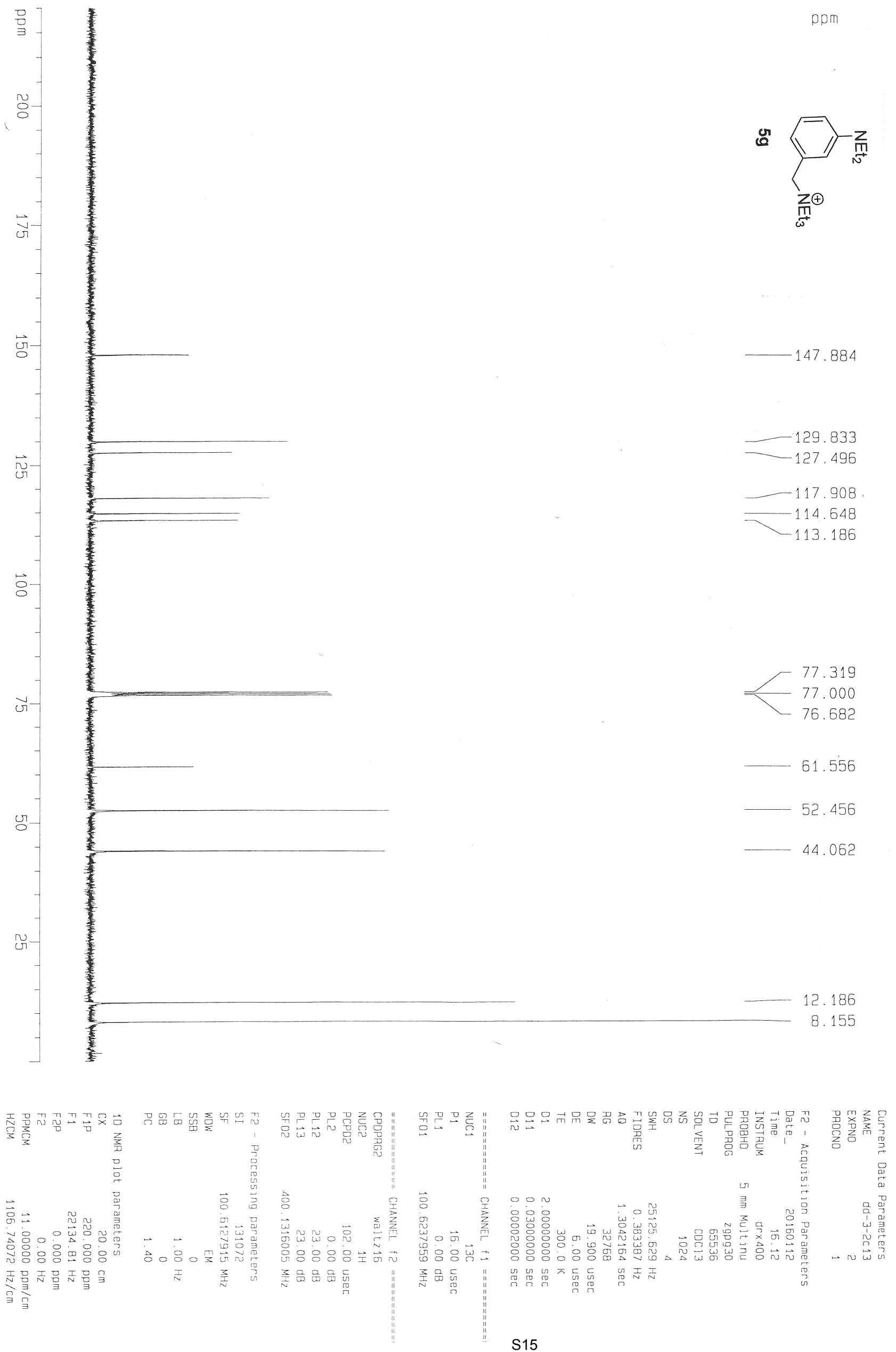


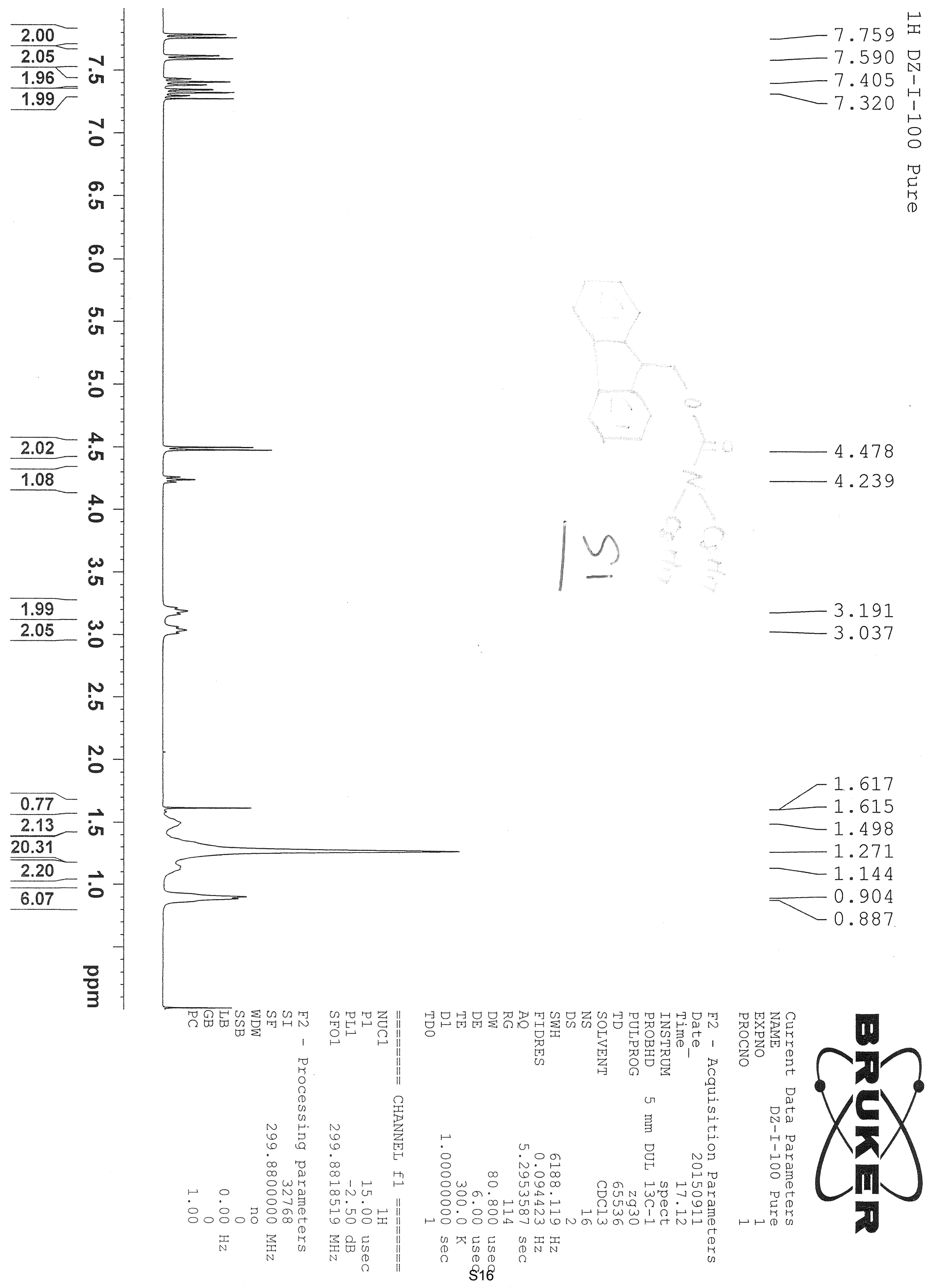



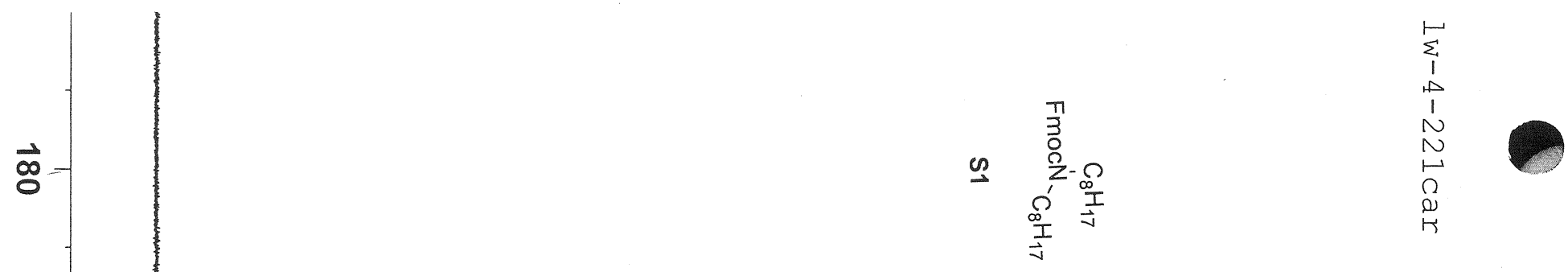

$\overrightarrow{8}$

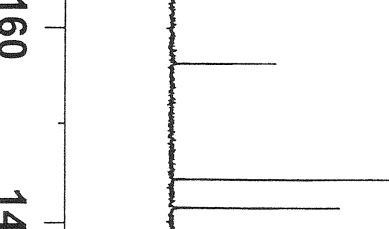

$\overrightarrow{\vec{B}}-\sqrt{ }$
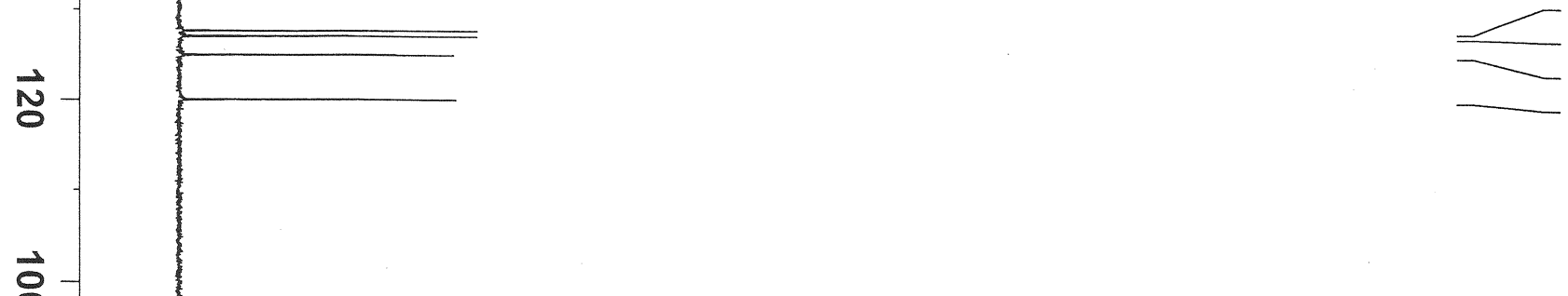

요

$\infty$
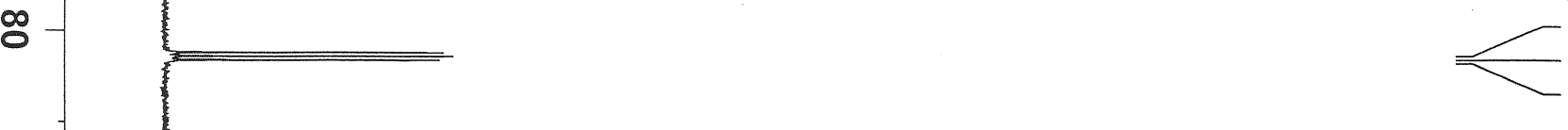

8
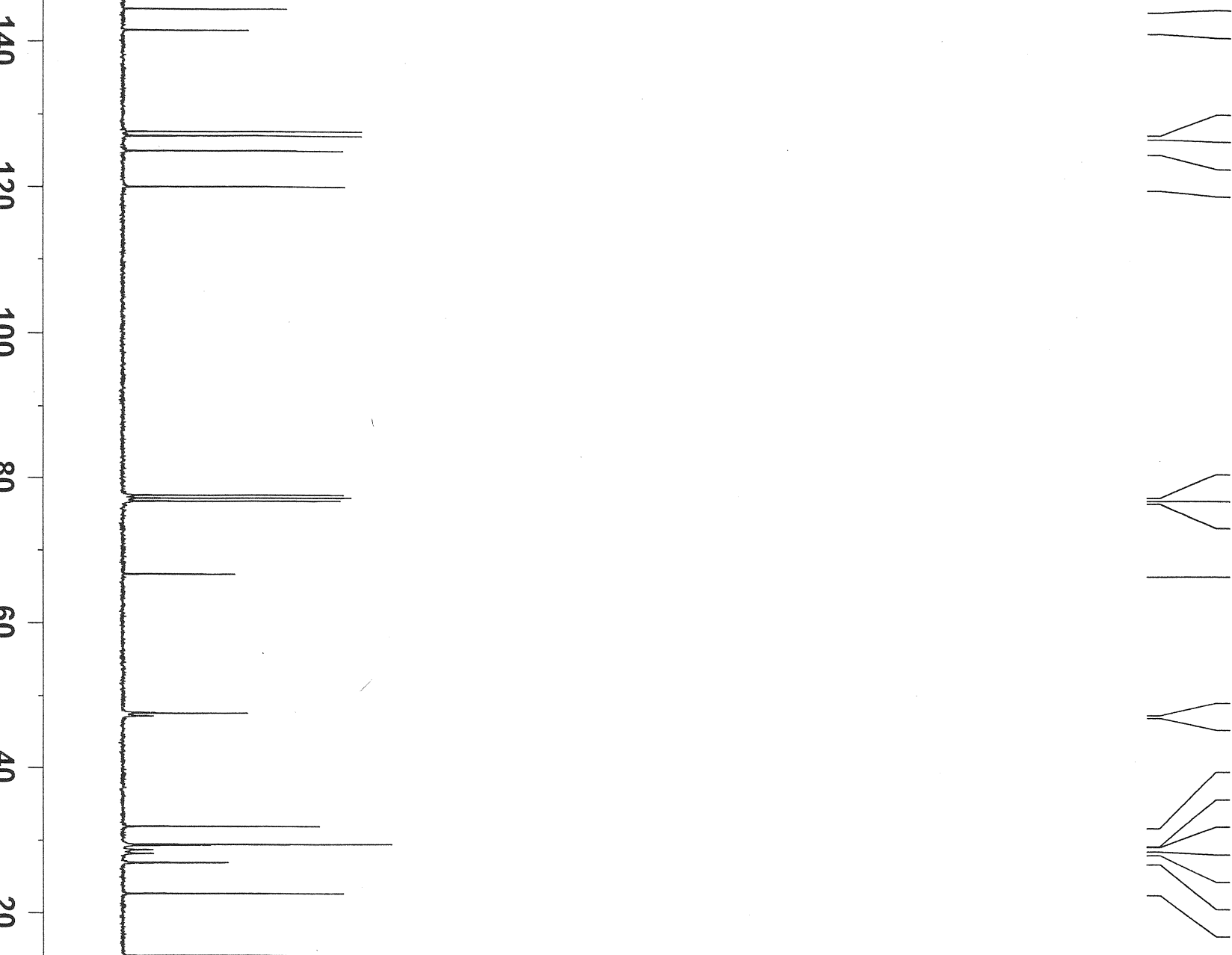

홓

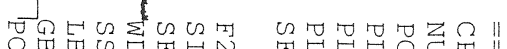

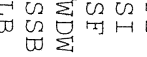

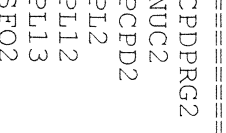

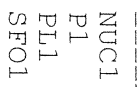

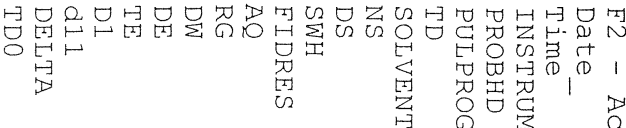

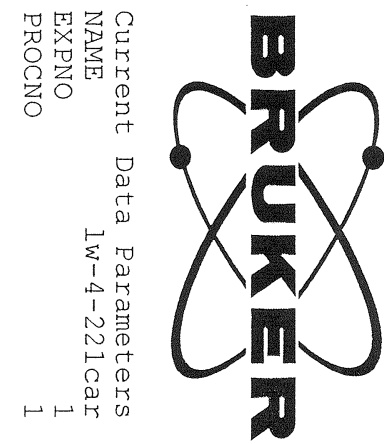

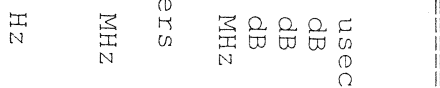

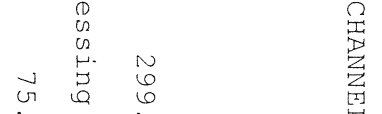

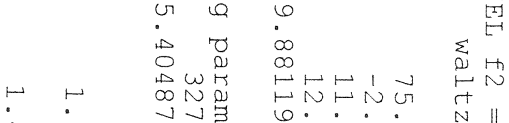

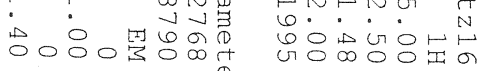

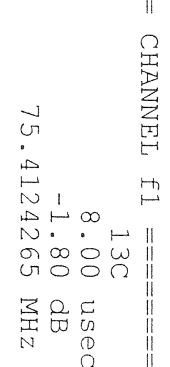

rON

$\begin{array}{lll}1 & 0 \\ 0 & 0 & 0 \\ 0 & 0 & 0 \\ 6 & 0 & 0 \\ 0 & 0 & 0\end{array}$

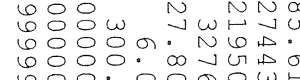

政

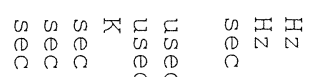




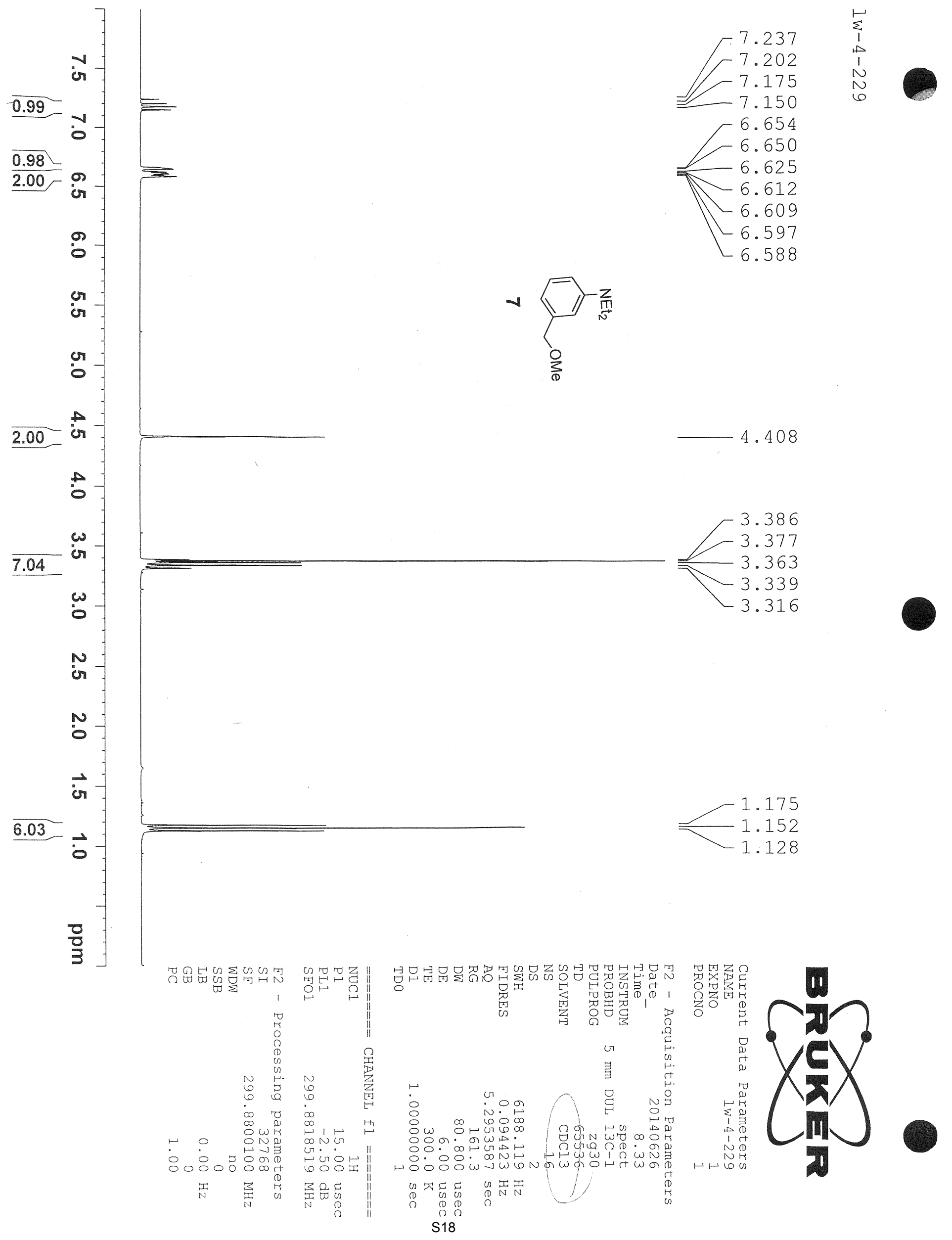




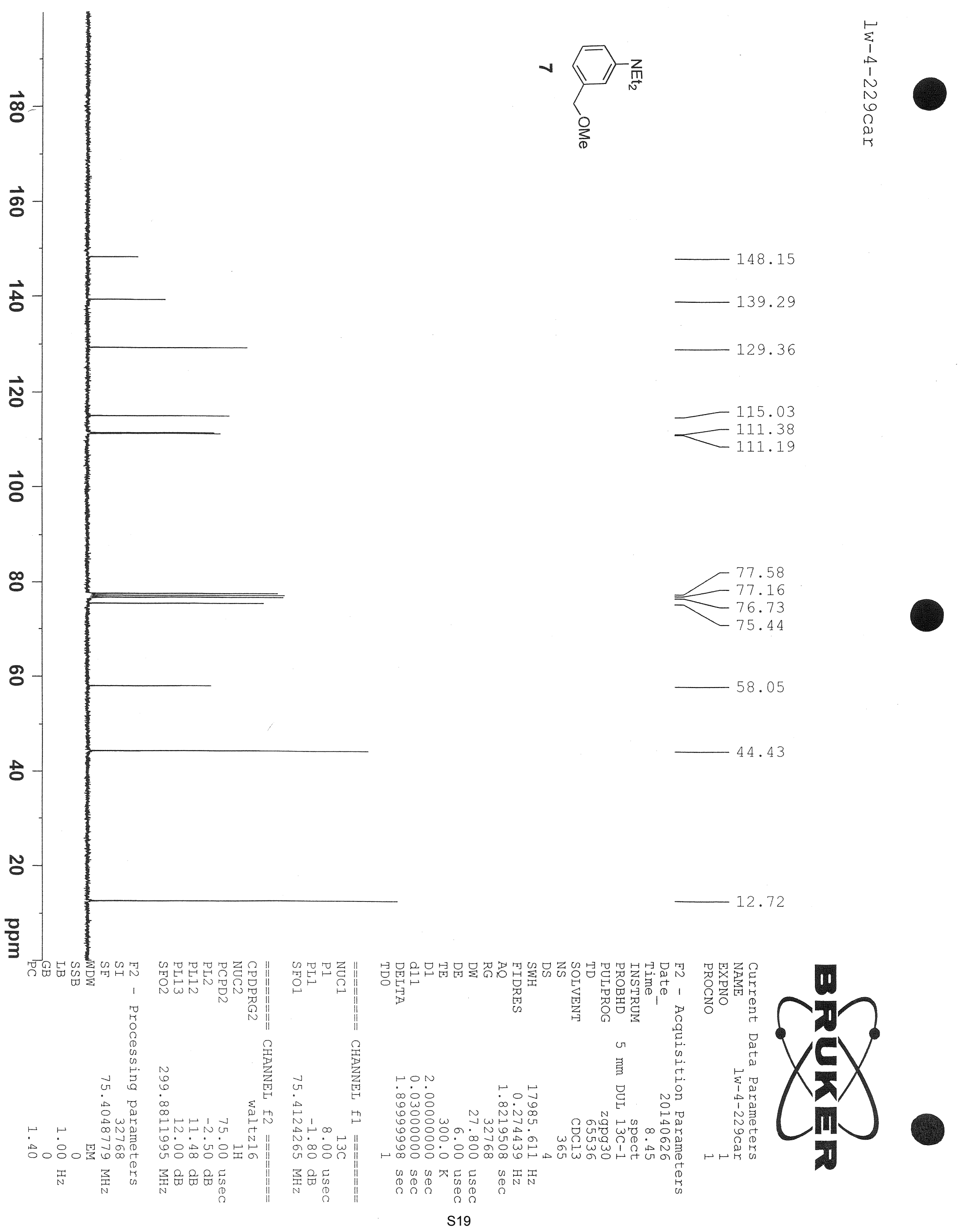




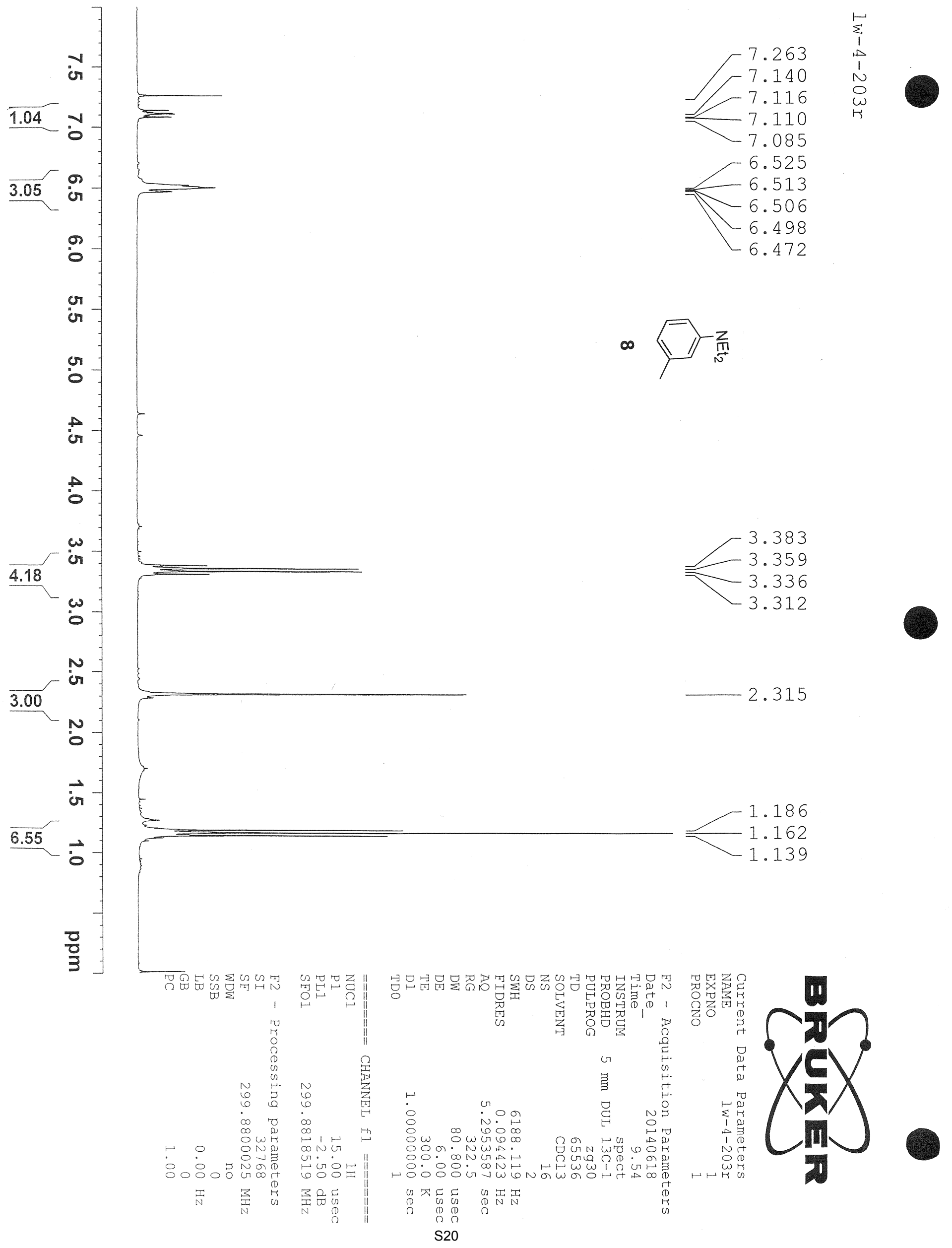




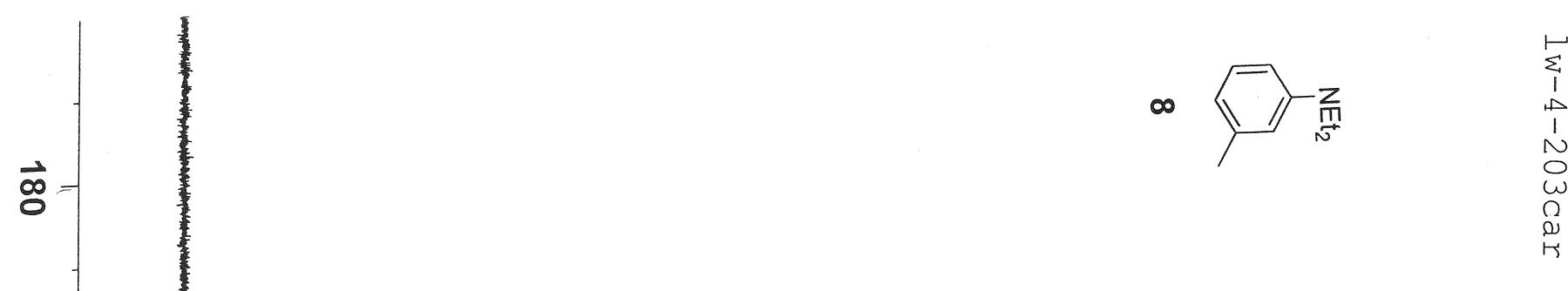

148.05

139.00

129.25

116.50

112.76

109.29

$\overrightarrow{\text { }}$

$\infty$
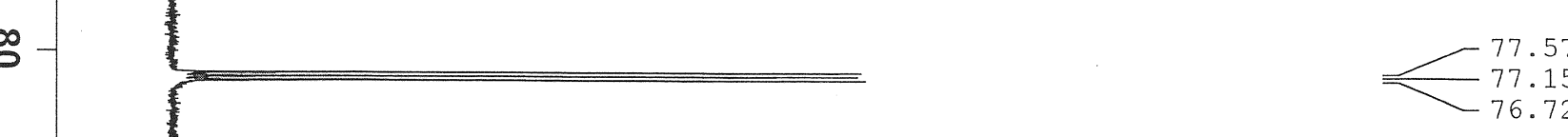

$-76.72$

8

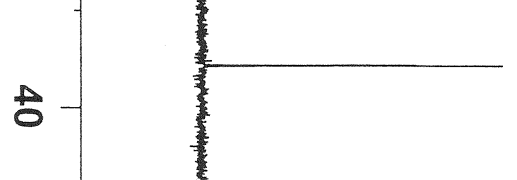

44.43

กั

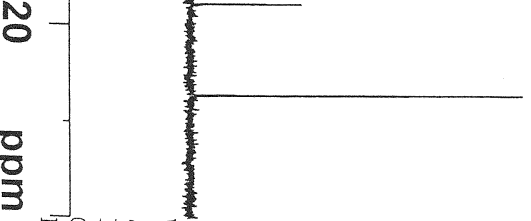

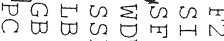

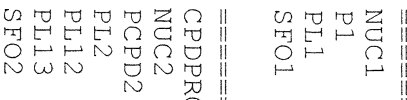

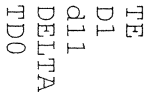

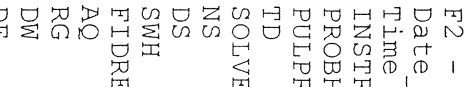
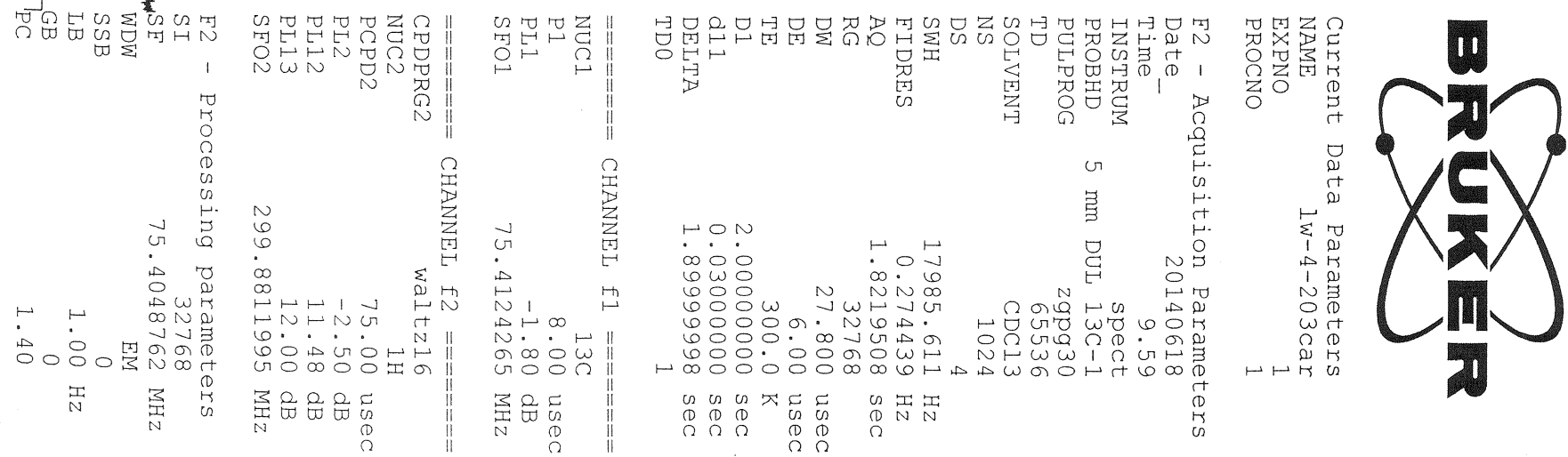

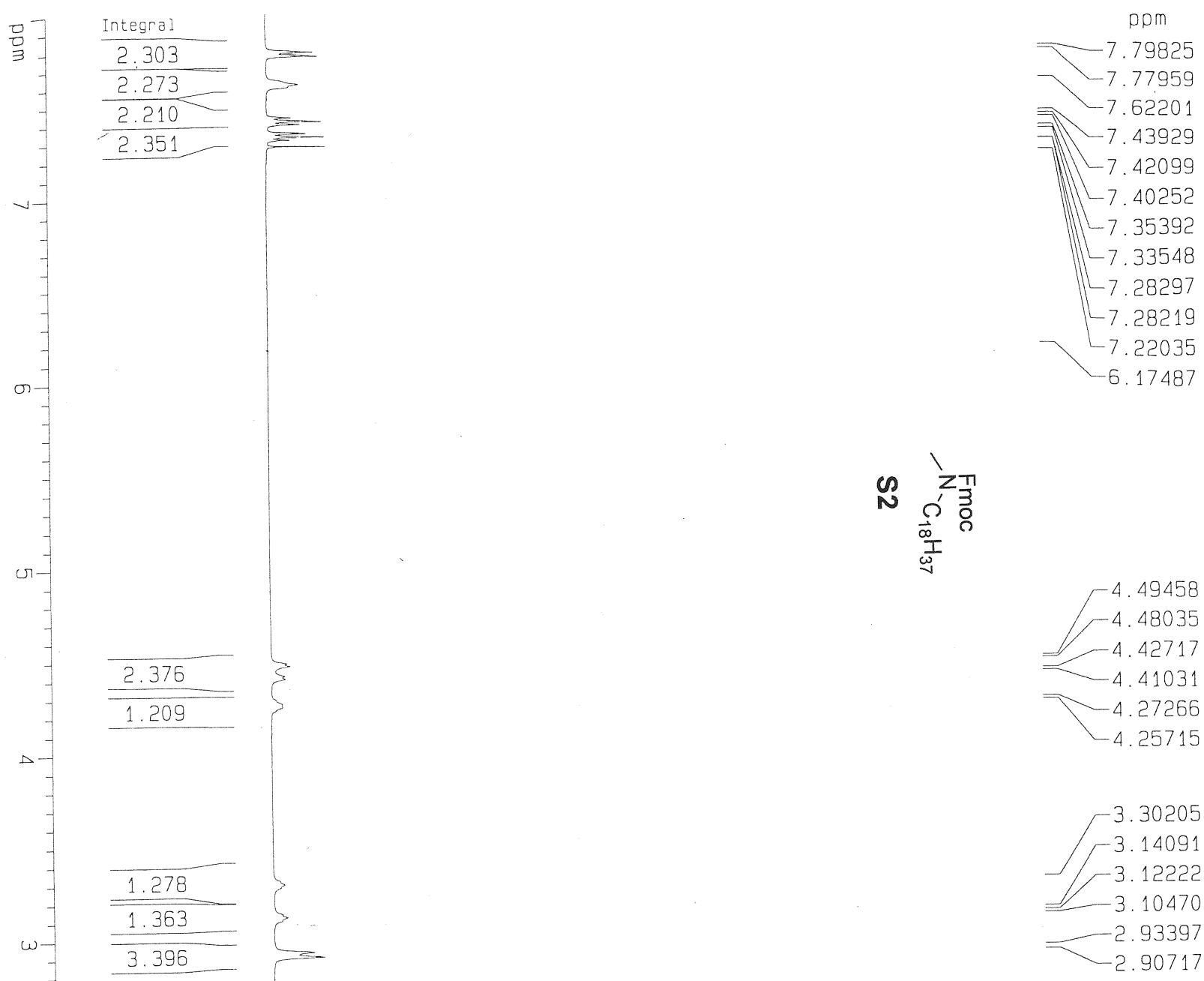

$-2.93397$

-2. 90717

-1.63557

$-1.62802$

$-1.55025$

$-1.38427$

$-1.36340$

$-1.28440$

$-1.17627$

$-1.06260$

$\int_{-0}^{1.06260}$

38.723
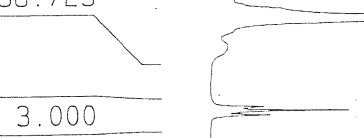

$-0.90798$

$-0.89059$

0.10167

$-0.03736$

$-0.03071$

$-0.02998$

$-0.02917$

$-0.02765$

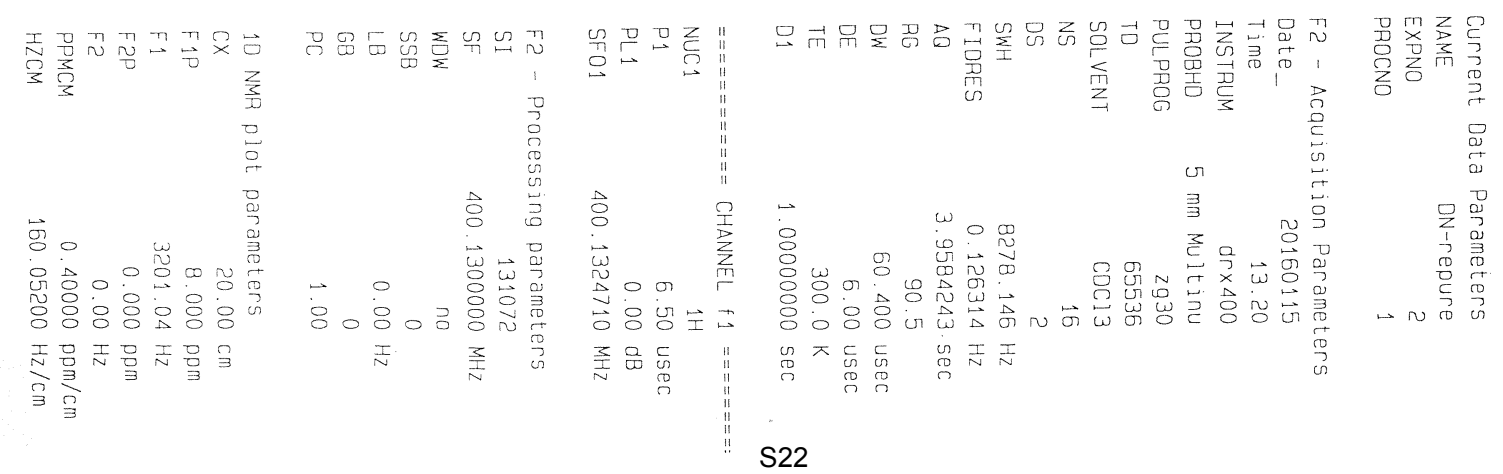




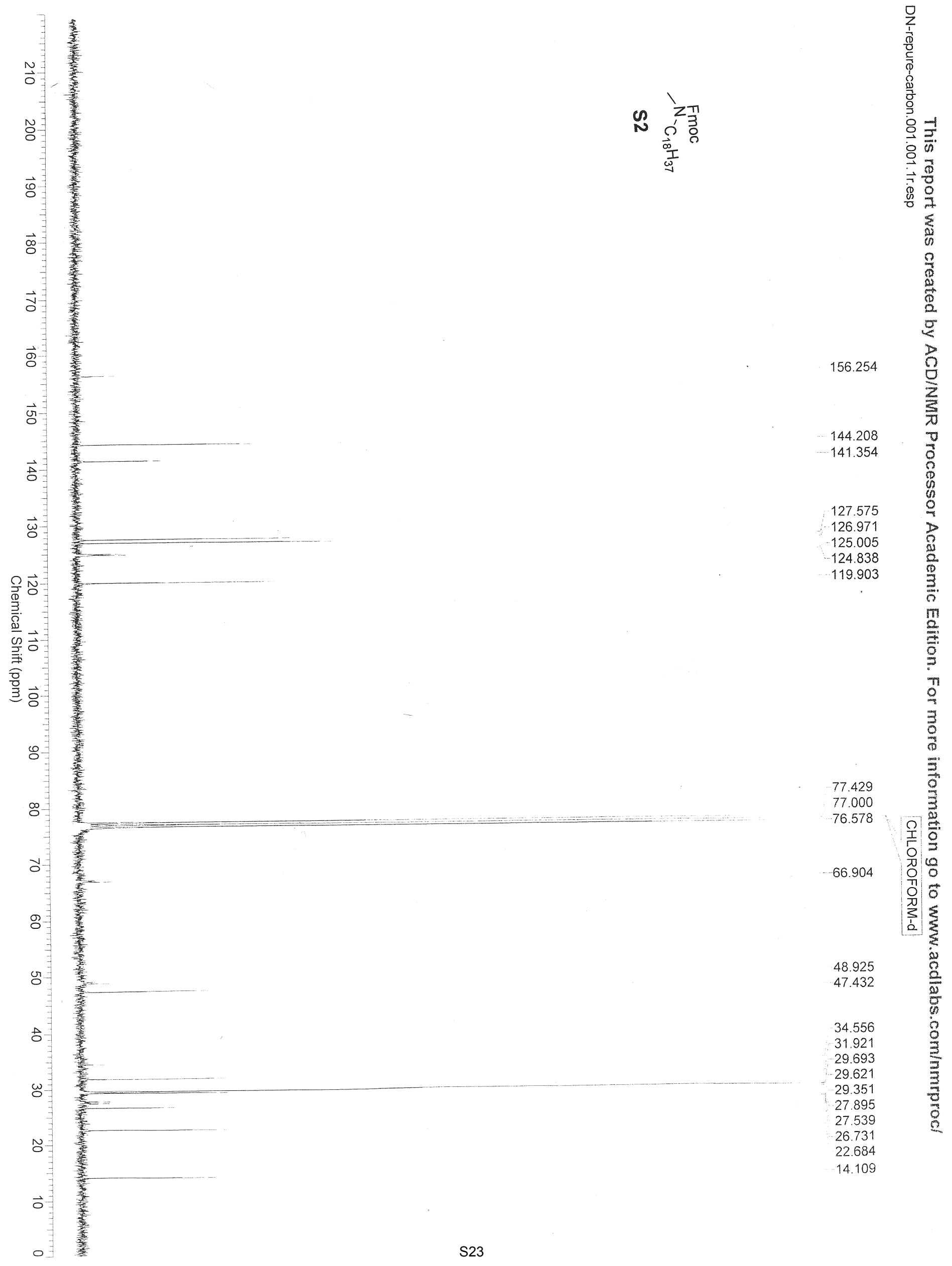

